\title{
A methodology for the preliminary design and performance prediction of high- pressure ratio radial-inflow turbines
}

\author{
Meroni, Andrea; Robertson, Miles; Martinez-Botas, Ricardo; Haglind, Fredrik
}

\author{
Published in: \\ Energy
}

Link to article, DOI:

10.1016/j.energy.2018.09.045

Publication date:

2018

Document Version

Peer reviewed version

Link back to DTU Orbit

Citation (APA):

Meroni, A., Robertson, M., Martinez-Botas, R., \& Haglind, F. (2018). A methodology for the preliminary design and performance prediction of high-pressure ratio radial-inflow turbines. Energy, 164, 1062-1078.

https://doi.org/10.1016/i.energy.2018.09.045

\section{General rights}

Copyright and moral rights for the publications made accessible in the public portal are retained by the authors and/or other copyright owners and it is a condition of accessing publications that users recognise and abide by the legal requirements associated with these rights.

- Users may download and print one copy of any publication from the public portal for the purpose of private study or research.

- You may not further distribute the material or use it for any profit-making activity or commercial gain

- You may freely distribute the URL identifying the publication in the public portal 


\section{Accepted Manuscript}

A methodology for the preliminary design and performance prediction of highpressure ratio radial-inflow turbines

Andrea Meroni, Miles Robertson, Ricardo Martinez-Botas, Fredrik Haglind

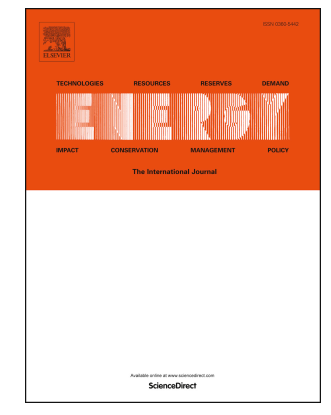

PII: $\quad$ S0360-5442(18)31805-X

DOI: $\quad$ 10.1016/j.energy.2018.09.045

Reference: EGY 13739

To appear in: Energy

Received Date: 2 May 2018

Revised Date: 24 July 2018

Accepted Date: 6 September 2018

Please cite this article as: Meroni A, Robertson M, Martinez-Botas R, Haglind F, A methodology for the preliminary design and performance prediction of high-pressure ratio radial-inflow turbines, Energy (2018), doi: 10.1016/j.energy.2018.09.045.

This is a PDF file of an unedited manuscript that has been accepted for publication. As a service to our customers we are providing this early version of the manuscript. The manuscript will undergo copyediting, typesetting, and review of the resulting proof before it is published in its final form. Please note that during the production process errors may be discovered which could affect the content, and all legal disclaimers that apply to the journal pertain. 


\title{
A methodology for the preliminary design and performance prediction of high-pressure ratio radial-inflow turbines
}

\author{
Andrea Meroni $^{\mathrm{a},{ }^{*}}$, Miles Robertson $^{\mathrm{b}}$, Ricardo Martinez-Botas ${ }^{\mathrm{b}}$, Fredrik Haglind ${ }^{\mathrm{a}}$ \\ ${ }^{a}$ Department of Mechanical Engineering, Technical University of Denmark, Nils Koppels Allé, Building 403, \\ 2800 Kongens Lyngby, Denmark; \\ ${ }^{b}$ Department of Mechanical Engineering, Imperial College London, City and Guilds Building, South Kensington \\ Campus, London SW7 2AZ, UK
}

${ }^{*}$ Corresponding author

Email addresses: andmer@mek.dtu.dk (Andrea Meroni), miles.robertson09@imperial.ac.uk (Miles Robertson),r.botas@imperial.ac.uk (Ricardo Martinez-Botas), frh@mek.dtu.dk (Fredrik Haglind)

\begin{abstract}
Modern power generation technologies, such as organic Rankine cycle power systems, require turboexpanders operating with high-efficiency and high power density. These features often lead to highpressure ratios machines, characterised by the presence of choking and supersonic flow conditions. This paper proposes a comprehensive methodology for the preliminary design and performance prediction of radial-inflow turbines operating at high-pressure ratios. A steady-state, mean-line model of a radialinflow turbine is developed including real-gas effects and a detailed modelling strategy for the treatment of choking flow conditions. In addition, a set of loss models tailored to high-pressure ratio radial-inflow turbines is developed. After a global sensitivity analysis, the model is calibrated by means of a multiobjective optimisation with a Genetic Algorithm and using the data of six high-pressure ratio turbines with total-to-total pressure ratios up to 5.8. The calibration method allows a significant reduction in the overall predicted deviation of the turbine isentropic efficiency and mass flow rate. The design model yields predicted deviations in isentropic efficiency within $\pm 3 \%$-points and the off-design model within $5 \%$. The methodology and the results are intended to be used as a benchmark for the future development of radial-inflow turbines in high-pressure ratio applications.
\end{abstract}

Keywords: radial inflow turbine, validation, mean-line model, high-pressure ratio, organic Rankine cycle

2010 MSC: 00-01, 99-00

\section{Introduction}

Table 1: RITs designed and tested at pressure ratios above 3 from the open literature.

\begin{tabular}{|l|l|c|l|c|}
\hline Author & Year & Application & Tested pressure ratio [-] & Fluid \\
\hline Hiett and Johnston [1,2] & 1963 & GT & $1.3-5.0$ & Air \\
\hline McLallin and Haas [3] & 1980 & GT & $1.2-4.7$ & Air \\
\hline Kidwell and Large [4] & 1980 & GT & $2.0-5.0$ & Air \\
\hline Rogo et al. [5] & 1984 & GT & $2.0-7.0$ & Air \\
\hline Ribaud and Mischel [6] & 1986 & GT & $2.97-3.8$ & Air \\
\hline Rogo [7] & 1986 & GT & $2.0-7.0$ & Air \\
\hline Rodgers [8] & 1990 & TC/GT & $3.6,3.9,4.3$ & Air \\
\hline Simonyi et al. [9] & 1991 & GT & $3.0-5.8$ & Air \\
\hline Pullen et al. [10] & 1993 & GT & $1.1-4.7$ & Air \\
\hline Huntsman et al. [11, 12] & 1992,1994 & GT & $4.7^{(*)}$ & Air \\
\hline Jones [13] & 1994 & GT & $1.0-9.0$ & Air \\
\hline
\end{tabular}




\begin{tabular}{|l|l|c|l|c|}
\hline Spence and Artt [14] & 1997 & RES & $1.3-4.0$ & Air \\
\hline Atkinson [15] & 1998 & RES & $1.3-3.7$ & Air \\
\hline Doran et al. [16] & 2001 & TC & $1.3-3.5$ & Air \\
\hline Feng et al. [17] & 2005 & GT & $1.1-3.1$ & Air \\
\hline Spence et al. [18] & 2007 & TC & $1.2-3.6$ & Air \\
\hline Deng [19] & 2007 & RES & $1.3-4.0$ & Air \\
\hline Fu et al. [20, 21] & 2012,2015 & GT & $1.1-3.1$ & Air \\
\hline Ino et al. [22] & 1991 & CR & $7.0-12.0$ & Helium \\
\hline Ghosh [23] & 2008 & CR & $1.8-5.9$ & Air/Nitrogen \\
\hline Larjola [24] & 1988 & ORC & $10.0^{(*)}$ & R114 \\
\hline Van Buijtenen et al. [25] & 2003 & ORC & $120.5^{(*)}$ & Toluene \\
\hline Pei et al. [26] & 2011 & ORC & $7.1^{(*)}$ & R123 \\
\hline Kang and Chung [27, 28] & 2011,2012 & ORC & $4.1^{(*)}$ & R245fa \\
\hline Han et al. [29] & 2014 & ORC & $3.2^{(*)}$ & R245fa \\
\hline Demierre et al. [30, 31] & $2014-2015$ & ORC & $3.1^{(-4.4}$ & R134a \\
\hline Kang [32] & 2016 & ORC & $4.1^{(*)}$ & R245fa \\
\hline Turunen-Saaresti et al. [33] & 2017 & ORC & $112.8^{(*)}$ & MDM \\
\hline
\end{tabular}

GT $=$ Gas Turbines. RES $=$ Research. TC $=$ Turbochargers. $\mathrm{CR}=$ Cryogenic systems. $\mathrm{ORC}=$ Organic Rankine cycles. ${ }^{(*)}=$ documented design point only.

Radial-inflow turbines (RITs) are used extensively within many areas of the power generation field. Conventional applications range from large-scale hydroelectric power plants to small-scale units used in automotive turbochargers, aircraft auxiliary power units, cryogenic systems, and space power generation [34]. In all these applications, the radial-inflow configuration features key advantages over its axial counterpart such as the lower cost and ease of manufacturing, higher efficiency, and reduced size and number of stages $[34,35]$. The specific requirements of the selected applications may result in a turbine operating at high-pressure ratio (HPR) conditions, usually above 3 . This may be particularly significant in cases where cost and size are limiting factors.

The pressure ratio across the turbine depends on the specifications of the thermodynamic cycle, i.e. heat source and heat sink temperatures, and on the selected working fluid. In the context of organic Rankine cycle (ORC) power systems, pressure ratios up to 100-150 [36, 37] can be achieved in combination with moderate to high heat source temperatures. Such pressure ratios are characterised by the presence of nozzle and/or rotor choking conditions and supersonic flows. The latter entail the formation of shock patterns and result in an unsteady nozzle-rotor fluid dynamic interaction which may compromise the mechanical integrity and the performance of the blade rows. Moreover, depending on the application, the working fluid operating at high pressure ratios might not behave like a perfect gas. For organic fluids, the expansion starts close to the critical point and typically ends far from the saturation line at the turbine outlet. In such conditions, the fluid exhibits a large change in the thermodynamic properties, making it important to consider real-gas effects. The aforementioned aspects make the design and performance prediction of HPR turbines significantly different from those of lower pressure ratio turbines, and therefore require numerical tools and strategies tailored for high-pressure ratio applications. 
Different authors, including Refs. [6, 14, 38-40], pointed out the lack of publicly available and welldocumented data regarding the RIT geometry and internal flow conditions, which hampers the development of reliable and accurate performance prediction tools. This lack of published stage performance data is even greater for HPR turbines. A compilation of RITs designed and tested at pressure ratios above 3 from the open literature is reported in Table 1. In order to fill this gap, Sauret [41] and $\mathrm{Li}$ et al. [42] resorted to aerodynamic investigations with CFD models on specific HPR turbines tested in the literature.

At the same time, the use of one-dimensional (or mean-line) models is often regarded as the most important step for the preliminary design and performance prediction of a turbine, and allows for significant cost and time savings in the whole turbine design process [36] compared to more advanced design methods. However, preliminary mean-line modelling strategies and validation studies for RITs operating at HPRs are very limited and the existing methods mostly rely on the data for low-pressure ratio conditions.

The first mean-line modelling strategies documented in the open literature were based on data of lowpressure ratio turbines [43-46]. These models did not consider real-gas equations of state as well as detailed choking considerations in their formulation. Since the 2000 s, real-gas equations of state could be embedded in the numerical models and other models were developed [39, 47, 48]. In recent years, other authors presented a number of mean-line models for the design and off-design analysis of RITs, especially for ORC power systems. However, only few authors included choking considerations which occur in the nozzle and/or in the rotor at high pressure ratios. Rahbar et al. [49], Da Lio et al. [50], and Mounier et al. [51] developed mean-line models to predict the design efficiency of RITs for ORC applications. The proposed models included the treatment of choking conditions at the design point only. Demierre et al. [31] developed a mean-line model of an ORC turbine considering also choking conditions, however, the authors did not present a detailed modelling strategy for the prediction of the different possible choking patterns in the turbine.

The mean-line method by Baines [52] is probably the most updated in the field as it has been object of refinements and improvements, see Refs. [53, 54]. Based on the previous work by Baines [52-54], Qiu and Baines [2] were the first to propose a mean-line method to compute the turbine flow capacity for unchoked and choked conditions, and for the subsonic, transonic and supersonic flow regimes. The authors validated their model using three test cases. Although Qiu and Baines [2] presented a method which considered choking conditions for HPR turbines, they did not present the details of their numerical modelling strategy and the geometry and flow data of the test cases are not fully available in the open literature or come from private communications, respectively.

Another fundamental aspect in the development of a mean-line model is the validation and/or calibration process with experimental data. Glassmann [55] calibrated his model to the data of six RITs, of which two were HPR turbines. However, the loss models were evaluated only at the design point. The study by Qiu and Baines [2] employed loss model correlations that were developed and calibrated considering the data of low-pressure ratio turbines at the design point, see Refs. [52-54], and it is arguable whether these are fully representative for HPR turbine applications, especially at off-design operation.

The objective of this paper is to present a comprehensive method for the performance prediction and for the validation of RITs operating at HPR conditions based on the existing data sets of HPR turbines in the open literature. To this end, the paper presents a complete approach for turbine design and offdesign modelling, calibration, validation, and analysis of the results. The work is limited to steadystate conditions. A mean-line model for the design and off-design analysis of RITs was developed and different strategies for the treatment of unchoked and choked conditions as well as subsonic and supersonic flows are presented. The model is conceived to include real-gas equations of state and a general formulation of the governing equations, in order to adapt the methodology to any working fluid and operating condition. A global sensitivity analysis based on the Monte Carlo method was applied to identify the significance level of the calibration coefficients with respect to the choking mass flow rate and the output isentropic efficiency. Afterwards, the calibration methodology is presented, where the turbine loss models are calibrated against the data of six HPR nozzled turbines 
from the open literature. In order to evaluate the suitability of the model, the results of the calibration were assessed by validation with two other test cases, one of which is an ORC turbine, whose features are different from the turbines used in the calibration process.

This paper contains the following novel contributions: (1) it presents in detail a mean-line modelling strategy for the treatment of choking conditions in the nozzle and the rotor at design and off-design conditions; (2) it presents an optimisation-based calibration method, which seeks to minimise the predicted deviation across every measured operating point contained within each of the test cases; (3) it provides a set of loss models tailored to HPR-RITs. The methodology and the results are intended to be used as a benchmark for the future development of radial-inflow turbines in high-pressure ratio applications.

Compared to the work by Baines [52-54] and to the most recent works in the field, i.e. Refs. [31, 50, $51,56]$, this paper extends the design and off-design methodology to high pressure ratios.

The paper is structured as follows: Section 2 presents the turbine test cases, the modelling strategies for design and off-design, and the methods for the sensitivity analysis, calibration and validation. Section 3 presents the results of the calibration. Section 4 discusses the results. The conclusions are drawn in Section 5.

\section{Methods}

\subsection{Performance prediction methodology}

Figure 1: Schematic of the radial-inflow turbine geometry.

Figure 2: Illustration of the possible turbine flow patterns occurring at off-design conditions: (a) Nozzle and rotor unchoked; (b) rotor choked and nozzle unchoked; (c) nozzle choked and rotor unchoked; (d) nozzle and rotor choked.

Figure 3: Modelling strategy for high-pressure ratio RITs: (a) preliminary design model; (b) off-design model.

This work employed a steady-state, mean-line model for the performance prediction of RITs at design and off-design conditions. The model has been conceived and implemented with the following objectives: (i) to include a complete and consistent numerical strategy for the design and performance prediction considering unchoked and choked flow conditions; (ii) to develop a tool which is general, and can be applicable to any fluid, operating condition or HPR application of interest; (iii) to ensure numerical robustness, stability and to allow for a short computational time. The model was written in the MATLAB language [57] and followed a mean-line approach, for which the thermodynamic and flow conditions were computed at the mean line in the turbine meridional plane, and were representative of mass-weighted averaged conditions over the whole section. This work focused on the modelling of the nozzle, the nozzle-rotor interspace, and of the rotor. Figure 1 depicts a schematic of the radial-inflow turbine highlighting the main stations, the terminology and the symbols used in this paper.

The thermodynamic and flow conditions in the main modelling stations were computed by the simultaneous solution of mass continuity, energy balance, and loss equations. The fluid properties were computed by means of real-gas equations of state using the thermodynamic library CoolProp [58].

Each blade row can feature two distinguished flow patterns, corresponding to unchoked and choked flow conditions, respectively. The blade row is choked when the flow reaches sonic conditions at the point of minimum flow area, identified as the throat. For an isentropic process through a bladed element in the relative coordinate system, it can be shown that the maximum mass flow rate per unit area occurs at sonic conditions [34]. Figure 2 illustrates that there are four possible combinations of the flow patterns, identifying the four physical situations occurring in the turbine: (a) both the nozzle and the rotor are unchoked, (b) the nozzle is unchoked and the rotor is choked, (c) the nozzle is choked and the rotor is unchoked, and (d) both the nozzle and the rotor are choked. 
Different strategies can be used for design and off-design performance prediction using a mean-line model, and the reader is referred to Ref. [59] for a general overview of the topic. Figure 3 shows the modelling modelling strategies adopted in this work.

Figure 3 (a) depicts the workflow of the preliminary design model. The model inputs are the inlet total temperature $T_{01}$ and pressure $\mathrm{p}_{01}$, the rotational speed $\mathrm{N}$, the mass flow rate $\dot{\mathrm{m}}$, and the stage totalto-static pressure ratio $\mathrm{PR}_{\mathrm{ts}}$. In addition, a set of decision variables needs to be given as an input. This set often consists of non-dimensional variables related to the turbine geometry and turbine loading conditions, which allows expressing the design in a more general formulation. The reader is referred to Refs. $[60,61]$ for examples of possible sets of design variables. The strategy shown in Figure 3(a) applies to a predefined set of input variables, and a dedicated optimisation procedure needs to be applied in order to determine the optimal set of inputs. For a set of input decision variables, the design modelling strategy starts by identifying where choking occurs since the maximum turbine flow capacity is limited by the mass flow rate at choking conditions (Step 0). The mass continuity, energy balance, and loss equations for the nozzle are expressed, respectively, as

$$
\begin{aligned}
& \mathrm{C}_{2}=\frac{\dot{\mathrm{m}}}{\rho_{2} \cdot \cos \left(\alpha_{2}\right) \cdot \mathrm{A}_{2}\left(1-\mathrm{BF}_{2}\right)} \\
& \mathrm{h}\left(\rho_{2}, \mathrm{~T}_{2}\right)=\mathrm{h}_{01}-\frac{1}{2} \mathrm{C}_{2}^{2}(2) \\
& \sum_{\mathrm{n}=1}^{\mathrm{n}_{\text {losses }}} \Delta \mathrm{h}_{\text {loss }, \mathrm{n}}-\mathrm{h}\left(\rho_{2}, \mathrm{~T}_{2}\right)+\mathrm{h}\left(\mathrm{p}_{2}, \mathrm{~s}_{1}\right)=0
\end{aligned}
$$

where $\rho_{2}, \alpha_{2}, \mathrm{~A}_{2}, \mathrm{C}_{2}, \mathrm{p}_{2}$ are the density, flow angle, flow area, absolute velocity, and static pressure at the nozzle outlet, respectively. In Eq. 1, the blockage factor $\mathrm{BF}_{2}$ may be introduced to account for reduction in effective area due to the metal blockage and boundary layer effects. The term $h$ denotes the specific enthalpy, and $\mathrm{h}_{01}$ and $\mathrm{s}_{1}$ are the total specific enthalpy and the specific entropy computed at the nozzle inlet, respectively. The term $\Delta \mathrm{h}_{\text {loss, } \mathrm{n}}$ represents the specific loss contribution in the blade row, which is calculated with an empirical correlation, see Sec. 2.2. For unchoked flow conditions, the nozzle exit flow angle was computed using an empirical correlation, see Sec. 2.2. For given nozzle inlet conditions, the solution strategy adopted above allows expressing the left-hand side of Eq. 3 as a function of $\rho_{2}$ and $\dot{\mathrm{m}}$, as illustrated in Figure 4.

\section{Figure 4: Identification of the choking point for a blade row.}

For a given value of mass flow rate, the function at the left hand side of Eq. 3 is non-monotonic with a concave shape and a single peak. In the methodology presented in this work, the condition at which the maximum of this function crosses the abscissa was identified as the choking condition. For small values of $\dot{m}$, when the peak is above the abscissa, there exist two values of $\rho_{2}$ which satisfy Eq. 3 . The larger value corresponds to subsonic flow conditions, whereas the smaller value relates to supersonic flow conditions. By increasing the mass flow rate, the maximum of the curve shifts downwards, and eventually intersects the abscissa. Therefore, choking occurs when the subsonic and supersonic solutions coincide. When the mass flow rate exceeds the choking value, the curves in Figure 4 show that there is no solution to the system of equations. In this case, a different set of input design variables needs to be provided as an input in order to allow for a higher design mass flow rate.

If the nozzle is unchoked, the model solves the set of nozzle Eqs. 1-3 (Step 1) and the mass continuity, the energy balance, the momentum balance and the loss equation in the nozzle-rotor interspace (Step 2), respectively, as follows: 


$$
\begin{aligned}
& \mathrm{C}_{4}=\frac{\dot{\mathrm{m}}}{\rho_{4} \cdot \cos \left(\alpha_{4}\right) \cdot \mathrm{A}_{4}\left(1-\mathrm{BF}_{4}\right)} \\
& \mathrm{h}\left(\rho_{4}, \mathrm{~T}_{4}\right)=\mathrm{h}_{01}-\frac{1}{2} \mathrm{C}_{4}^{2} \\
& \frac{\mathrm{C}_{3} \sin \alpha_{3}}{\mathrm{C}_{4} \sin \alpha_{4}}=\frac{\mathrm{r}_{4}}{\mathrm{r}_{3}}+\frac{2 \pi \mathrm{C}_{\mathrm{f}} \rho_{4} \mathrm{C}_{4} \sin \alpha_{4}\left(\mathrm{r}_{3}^{2}-\mathrm{r}_{3} \mathrm{r}_{4}\right)}{\dot{\mathrm{m}}} \\
& \Delta \mathrm{h}_{\mathrm{vs}, \text { loss }}-\mathrm{h}\left(\rho_{4}, \mathrm{~T}_{4}\right)+\mathrm{h}\left(\mathrm{p}_{4}, \mathrm{~s}_{3}\right)=0
\end{aligned}
$$

where $\Delta \mathrm{h}_{\mathrm{vs}, \text { loss }}$ is the vaneless space loss and $\mathrm{C}_{\mathrm{f}}$ is the friction factor, which can be estimated with empirical models. The formulation of Eq. 6 was based on the analysis by Stanitz [62], as reported by Whitfield and Baines [63]. The system of Eqs. 4-7 was solved using a trust region solver in MATLAB [57] for a given set of guess values for $\alpha_{4}$ and $\rho_{4}$. Afterwards, the model evaluates whether the rotor is choked (Step 3). To this end, the mass continuity, the energy balance and the loss equations in the rotor were solved in its relative coordinate system, as follows:

$$
\begin{aligned}
& \mathrm{W}_{5}=\frac{\dot{\mathrm{m}}}{\rho_{5} \cdot \cos \left(\beta_{5}\right) \cdot \mathrm{A}_{5}\left(1-\mathrm{BF}_{5}\right)} \\
& \mathrm{h}\left(\rho_{5}, \mathrm{~T}_{5}\right)=\mathrm{I}_{4}-\frac{1}{2} \mathrm{~W}_{5}^{2}+\frac{1}{2} \mathrm{U}_{5}^{2} \\
& \sum_{\mathrm{n}=1}^{\mathrm{n}_{\text {loss }}} \Delta \mathrm{h}_{\text {loss } \mathrm{n}}-\mathrm{h}\left(\rho_{5}, \mathrm{~T}_{5}\right)+\mathrm{h}\left(\mathrm{p}_{5}, \mathrm{~s}_{4}\right)=0
\end{aligned}
$$

where $\mathrm{I}_{4}=\mathrm{h}_{4}+0.5 \mathrm{~W}_{4}^{2}-0.5 \mathrm{U}_{4}^{2}$ is the rothalpy term. In the design mode, the pressure at the rotor exit, $\mathrm{p}_{5}$, was specified by the required stage pressure ratio, and the flow angle $\beta_{5}$ was determined in order to match $\mathrm{p}_{5}$. In the off-design mode, under unchoked conditions, the rotor exit pressure was unknown, and the rotor exit flow angle was computed using an empirical correlation, see Sec. 2.2. Eq. 10 was expressed as a function of the rotor throat density $\rho_{5}$, showing a trend similar to that in Figure

4. However, in this case, the loss equation was also dependent on the turbine rotational speed. Similarly to the nozzle modelling, if the rotor was already choked, the design routine ended. Alternatively, the rotor equations were solved and the turbine design was completed by the postprocessing of the data.

Figure 3(b) shows the off-design modelling strategy. In this case an existing turbine design, or calculated as in Figure 3(a), was the input and turbine performance maps were generated as the output. The model inputs were the same as those of the design model, except that the full turbine geometry was given as well. The mass flow rate $\dot{\mathrm{m}}$ was provided as an input for the generation of performance maps when the turbine was not choked. If the turbine is choked, the mass flow rate is constant, and the outlet pressure can assume an infinitude of values. Hence, in this case, the static pressure at the turbine outlet was also specified. The workflow of Figure 3(b) applies to a single speed line, and an iterative process was implemented to generate the full performance maps.

The off-design modelling strategy started by evaluating whether, for the given input conditions, the nozzle or the rotor is the first to choke (Step 0). The set of Eqs. 1-3 is used for the nozzle. In Step 0, the nozzle choking mass flow rate is found by determining the zero of the locus of maxima of Eq. 3. Afterwards, the algorithm evaluates whether the rotor was already choked at the nozzle choking mass flow rate by solving Eq. 4-10. Like in the design strategy, the off-design methodology evaluates whether the rotor choking mass flow rate is smaller than the nozzle choking mass flow rate, and follows two different paths according to the result. Steps 1a-3a in Figure 3(b) relate to the 
configurations 1) and 2) of Figure 2, where the rotor chokes first. Steps $1 b-4 b$ in Figure 3 relate to the configurations 1), 3) and 4) of Figure 2, where the nozzle chokes first. If the rotor choked first, the choking mass flow rate and the choking density were found by determining the zero of the locus of maxima of Eq. 10 (Step 1a). Conversely, if the nozzle chokes first, the algorithm identifies the rotor choking point occurring at higher values of stage expansion ratio (Step 1 b). A numerical search method was used to find the zero of Eqs. 8-10 by changing the rotor inlet pressure. The corresponding values of nozzle and stage pressure ratio were then recorded and used in the subsequent steps.

Nozzle and rotor unchoked (Steps $2 a$ and $2 b$ ). The performance maps were generated by varying the mass flow rate up to the choking point. Equations 1-10 were sequentially solved for each value of mass flow rate, finding the corresponding value of pressure ratio.

Nozzle unchoked and rotor choked (Step $3 a$ ). When the rotor choking point was reached, the mass flow rate was kept constant, and the nozzle operation was fixed since any further expansion dowstream the rotor could not affect the conditions upstream the throat [34]. In this case, the rotor choking mass flow rate as well as the total-to-static pressure ratio of the stage were provided as inputs to the turbine model, and any further expansion was allowed by means of a post-expansion process after the throat. The value of choking density, previously calculated in Step 1a, was used to determine the values of the thermodynamic and flow conditions at the throat by applying mass continuity and the energy balance, Eqs. 8 and 9. The rotor exit density, $\rho_{6}$, after the post-expansion was found by solving the energy and mass balances and the post-expansion loss equation between the rotor throat and the exit as follows:

$$
\begin{aligned}
& \mathrm{W}_{6}=\sqrt{2 \cdot\left(\mathrm{I}_{4}-\mathrm{h}\left(\rho_{6}, \mathrm{p}_{6}\right)\right)+\mathrm{U}_{6}^{2}} \\
& \beta_{6}=-\cos ^{-1}\left[\dot{\mathrm{m}}_{\mathrm{ch}, \text { rot }} /\left(\rho_{6} \mathrm{~W}_{6} \mathrm{~A}_{5}\left(1-\mathrm{BF}_{5}\right)\right)\right] \\
& \Delta \mathrm{h}_{\mathrm{pe}, \text { rot }}-\mathrm{h}\left(\rho_{6}, \mathrm{p}_{6}\right)+\mathrm{h}\left(\mathrm{p}_{6}, \mathrm{~s}_{5}\right)=0
\end{aligned}
$$

where $\Delta \mathrm{h}_{\mathrm{pe}, \text { rot }}$ represents the post-expansion loss, $\mathrm{s}_{5}$ is the entropy at the throat, and $\dot{\mathrm{m}}_{\mathrm{ch}, \mathrm{rot}}$ is the value of rotor choking mass flow rate.

Nozzle choked and rotor unchoked (Step 3b). The thermodynamic and flow parameters at the choked throat were found by applying mass and energy balances between the nozzle inlet and the throat. When the pressure ratio was larger than the choking value, a post-expansion was allowed at the nozzle outlet. In order to determine the conditions after the post-expansion, the energy and mass balances and the post-expansion loss equation, were solved, respectively, as follows:

$$
\begin{aligned}
& \mathrm{C}_{3}=\sqrt{2 \cdot\left(\mathrm{h}_{01}-h\left(\rho_{3}, \mathrm{p}_{3}\right)\right)} \\
& \alpha_{3}=\cos ^{-1}\left[\dot{\mathrm{m}}_{\mathrm{ch}, \mathrm{noz}} /\left(\rho_{3} \mathrm{C}_{3} \mathrm{~A}_{2}\left(1-\mathrm{BF}_{2}\right)\right)\right] \\
& \Delta \mathrm{h}_{\mathrm{pe}, \mathrm{noz}}-\mathrm{h}\left(\rho_{3}, \mathrm{p}_{3}\right)+\mathrm{h}\left(\mathrm{p}_{3}, \mathrm{~s}_{2}\right)=0
\end{aligned}
$$

In this case, $\Delta \mathrm{h}_{\text {pe,noz }}$ represents the post-expansion losses, $\mathrm{s}_{2}$ is the specific entropy at the throat, and $\dot{\mathrm{m}}_{\mathrm{ch}, \mathrm{rot}}$ is the rotor choking mass flow rate.

Both nozzle and rotor choked (Step $4 b$ ). When both the nozzle and the rotor were choked, any further expansion downstream the rotor exit was allowed by means of a post-expansion after the rotor throat using Eqs. 14-16. 


\subsection{Empirical models for losses and flow deviation}

The sets of equations described in Sec. 2.1 require the use of empirical models for the losses and the exit flow angles for each blade row. Typically, the information on possible blockage effects in the blade rows is provided empirically and depends on the specific test case. In this work, the best agreement with the experimental data was found using $\mathrm{BF}=0$ and, consequently, the blockage effects were neglected.

The loss correlations were based on the formulations by Baines [52], however some modifications were introduced. In contrast to the axial turbine field, for radial turbines there is a deep lack of techniques used to predict nozzle losses based on geometry and flow conditions [59]. In the literature, nozzle losses have been often neglected or considered of a much lower entity than the rotor losses [52]. However, experimental works [3, 64] on high-pressure turbines and numerical studies [65, 66] on very high-pressure ratio RITs suggest that a proper nozzle model, and associated losses, are paramount to obtain meaningful results.

In this work, three types of nozzle losses were considered: the passage loss, the trailing edge loss, and the post-expansion loss. Among the few available nozzle passage loss formulations, those by Rodgers [46] and Rohlik [67] appear to be the most reliable in the literature [68]. The formulation by Rodgers [46] was preferred since it directly relates the loss to geometry and flow parameters without resorting to the use of the boundary layer parameters, which are less straightforward to estimate. The nozzle passage loss correlation by Rodgers [46] assumes that the trailing edge and shock losses are negligible, provided that the trailing edge to chord ratio is less than $2 \%$ and that Mach numbers are lower than 1.2.

In order to fully represent HPR conditions, the losses associated to the trailing edge blockage and to high Mach numbers at the blade outlet were included in the present model. The trailing edge loss was modelled using the formulation by Glassman [55], which, according to Refs. [55, 69, 70], is based on the actual blade blockage and provides a more physical formulation than that based on the meridional velocity component adopted by Baines [52]. The post-expansion loss is based on the work by Aungier [39].

The vaneless space loss uses a conventional pipe-flow correlation by Khastner and Bhinder [43] often employed in the literature, see Refs. [59, 63, 69]. The friction factor in the interspace between nozzle and rotor was estimated using the following correlation proposed by Japikse [71]:

$\mathrm{C}_{\mathrm{f}}=\mathrm{k}\left(\frac{1.8 \cdot 10^{5}}{\mathrm{Re}_{4}}\right)^{0.2}$

Equation 17 was developed from the experimental measurements on a number of diffusers for centrifugal compressors and shows that the friction factor in unguided swirling flows decreases with the average Reynolds number at the exit of the vaneless space. Equation 17 was used to model the interspace loss in RITs following Whitfield and Baines [63]. Japikse [71] noted that the coefficient $\mathrm{k}$ in Eq. 17 varied between 0.005 and 0.02 in different applications and recommended to use the value 0.01 .

The rotor model included the evaluation of losses internal and external to the blade passages. The internal losses were modelled with the passage loss, clearance loss and incidence loss correlations by Baines [52]. Moreover, rotor trailing edge and post-expansion loss models were introduced in a similar way as those of the nozzle modelling. The external losses included the effect of the rotor disc friction, and these were modelled as a sudden enthalpy drop at constant static pressure following Whitfield and Baines [63], and were predicted according to the method suggested by Daily and Nece [72].

Table 2: Loss correlations.

\begin{tabular}{|l|l|l|}
\hline $\begin{array}{l}\text { Loss } \\
\text { mechanis }\end{array}$ & Loss model & $\begin{array}{l}\text { Referenc } \\
\text { e }\end{array}$ \\
\hline
\end{tabular}




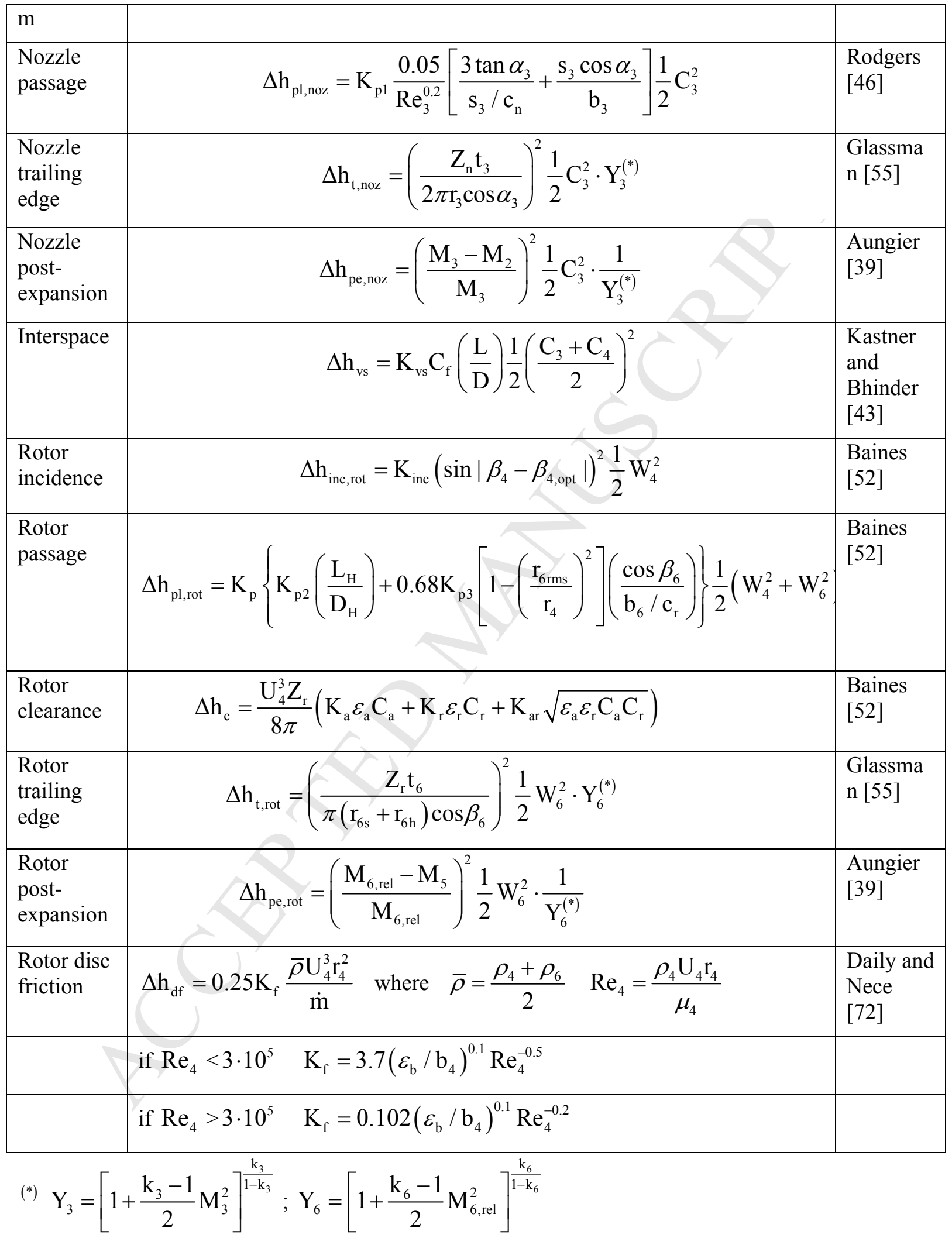

Table 2 shows the final set of loss models. The coefficients $\mathrm{K}_{\mathrm{p} 1}, \mathrm{~K}_{\mathrm{p} 2}, \mathrm{~K}_{\mathrm{p} 3}, \mathrm{~K}_{\mathrm{vs}}$ and $\mathrm{K}_{\mathrm{inc}}$ were initially selected for calibration in this work, although the final set for calibration was selected after a dedicated sensitivity analysis, see Sec. 2.3. 
Unlike within the axial-flow turbine field, there is a lack of well-established and reliable correlations for the deviation angle in RITs. The exit flow angle at unchoked conditions for the nozzle and the rotor was predicted using the cosine rule, where $\mathrm{o}$ is the throat opening and $\mathrm{s}$ is the vane spacing.

$\alpha_{2}=\cos ^{-1}\left(\mathrm{o}_{2} / \mathrm{s}_{2}\right) \beta_{5}=\cos ^{-1}\left(\mathrm{o}_{5} / \mathrm{s}_{5}\right)$

If the nozzle or the rotor operates at supersonic flow conditions, the off-design modeling strategy solves the post-expansion equations and determines the exit flow angle according to Eqs. 11-13 or Eqs. 14-16.

\subsection{Sensitivity analysis}

A sensitivity analysis was applied to the off-design turbine model in order to achieve the following: i) identify the most sensitive calibration coefficients with respect to the output mass flow rate and isentropic efficiency; ii) remove the calibration coefficients which resulted to be less sensitive to the changes in mass flow rate and efficiency, reducing the computational requirements of the simulations; iii) identify the range of values for which the calibration coefficients fulfil the choking conditions required by the test cases.

A global sensitivity analysis based on the Monte Carlo method [73] was employed. Compared to a local sensitivity analysis method, the global sensitivity analysis takes into account the mutual interactions between the different calibration coefficients. Since the Monte Carlo method is based on a probabilistic approach, the results of the sensitivity analysis were analysed in terms of their probability distribution. The Monte Carlo method was applied using a numerical model written in the MATLAB language [57], which is documented in Ref. [74]. A uniform probability distribution without correlation control was used for the input calibration coefficients. A study on the effects of increasing sampling size up to 1000 samples for each coefficient and operating point in the turbine map was performed. A number of 500 samples was selected since it provided a reasonable trade-off in terms of accuracy of the results and required computational time. Each speed line was divided into 50 points, corresponding to 25000 samples per speed line generated by the Monte Carlo method. The sensitivity analysis was applied to the turbine model using the test cases described in Sec. 2.4.

\subsection{Calibration method}

Table 3: Data of the HPR turbines selected for calibration.

\begin{tabular}{|c|c|c|c|c|c|c|c|}
\hline & $\begin{array}{l}\text { Test } \\
\text { case }\end{array}$ & $\begin{array}{l}\text { Meitner and } \\
\text { Glassman }\end{array}$ & $\begin{array}{l}\text { McLallin } \\
\text { et al. }\end{array}$ & $\begin{array}{l}\text { Simonyi } \\
\text { rotor } 1\end{array}$ & $\begin{array}{l}\text { Simonyi } \\
\text { rotor } 2\end{array}$ & Rogo & Atkinson \\
\hline & Ref. & [75] & {$[3]$} & [9] & [9] & [7] & {$[15]$} \\
\hline \multicolumn{8}{|c|}{ Input conditions } \\
\hline & 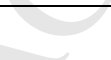 & & & & & & \\
\hline $\mathrm{T}_{01}$ & {$[\mathrm{~K}]$} & 377.778 & 322.2 & 477.78 & 477.78 & 394 & 418 \\
\hline $\mathrm{p}_{01}$ & {$[\mathrm{~Pa}]$} & 38610.6 & 137900 & 333706.3 & 333706.3 & 164000 & 354550 \\
\hline $\mathrm{N}$ & {$[\mathrm{rpm}]$} & $29550 ; 17730$ & $\begin{array}{l}9437- \\
34602\end{array}$ & $\begin{array}{l}17927- \\
21911\end{array}$ & $\begin{array}{l}15138- \\
22708\end{array}$ & $\begin{array}{l}12751- \\
15939\end{array}$ & $\begin{array}{l}26277- \\
40795\end{array}$ \\
\hline \multicolumn{8}{|c|}{ Stator } \\
\hline $\mathrm{b}_{1}$ & {$[\mathrm{~m}]$} & 0.0147 & 0.0109 & 0.021 & 0.021 & 0.015 & 0.008 \\
\hline $\mathrm{b}_{3}$ & {$[\mathrm{~m}]$} & 0.015 & 0.008 & 0.012 & 0.012 & 0.015 & 0.008 \\
\hline
\end{tabular}




\begin{tabular}{|c|c|c|c|c|c|c|c|}
\hline $\mathrm{r}_{1}$ & {$[\mathrm{~m}]$} & 0.073 & 0.097 & 0.224 & 0.224 & 0.251 & 0.111 \\
\hline$r_{3}$ & {$[\mathrm{~m}]$} & 0.060 & 0.084 & 0.194 & 0.194 & 0.194 & 0.092 \\
\hline$Z_{n}$ & {$[-]$} & 14 & 29 & 36 & 36 & 15 & 17 \\
\hline$t_{3}$ & {$[\mathrm{~m}]$} & 0.001 & 0.001 & 0.0003 & 0.0003 & 0.003 & 0.0012 \\
\hline$\alpha_{3 \mathrm{~b}}$ & {$\left[^{\circ}\right]$} & 72.47 & 76 & 70 & 70 & 77 & 76 \\
\hline $\mathrm{o}_{2}$ & {$[\mathrm{~m}]$} & 0.0073 & 0.0036 & 0.0091 & 0.0092 & 0.0174 & 0.0095 \\
\hline \multicolumn{8}{|c|}{ Rotor } \\
\hline $\mathrm{b}_{4}$ & {$[\mathrm{~m}]$} & 0.015 & 0.008 & 0.012 & 0.012 & 0.016 & 0.0077 \\
\hline $\mathrm{r}_{4}$ & {$[\mathrm{~m}]$} & 0.058 & 0.075 & 0.185 & 0.185 & 0.177 & 0.0867 \\
\hline$r_{6 s}$ & {$[\mathrm{~m}]$} & 0.041 & 0.047 & 0.118 & 0.118 & 0.114 & 0.0609 \\
\hline$r_{6 h}$ & {$[\mathrm{~m}]$} & 0.014 & 0.023 & 0.076 & 0.076 & 0.051 & 0.0261 \\
\hline$\beta_{4 \mathrm{~b}}$ & {$\left[{ }^{\circ}\right]$} & 0 & 0 & 0 & 0 & 0 & 0 \\
\hline$\beta_{6 \mathrm{~b}}$ & {$\left[{ }^{\circ}\right]$} & -56.86 & -58 & -55.3 & -53.86 & -60 & -60 \\
\hline$Z_{r}$ & {$[-]$} & 22 & 12 & 14 & 14 & 13 & 14 \\
\hline$t_{6}$ & {$[\mathrm{~m}]$} & 0.0002 & 0.004 & 0.001 & 0.001 & 0.00076 & 0.0024 \\
\hline $\mathrm{O}_{5}$ & {$[\mathrm{~m}]$} & 0.0048 & 0.0065 & 0.02 & 0.02 & 0.01706 & 0.0223 \\
\hline $1_{z}$ & {$[\mathrm{~m}]$} & 0.040 & 0.04572 & 0.046 & 0.043 & 0.107 & 0.0399 \\
\hline$\varepsilon_{\mathrm{a}}$ & {$[\mathrm{m}]$} & 0.0003 & 0.0003 & 0.0005 & 0.0002 & 0.0004 & 0.00075 \\
\hline$\varepsilon_{\mathrm{r}}$ & {$[\mathrm{m}]$} & 0.0004 & 0.0003 & 0.0002 & 0.0004 & 0.0004 & 0.0004 \\
\hline$\varepsilon_{\mathrm{b}}$ & {$[\mathrm{m}]$} & 0.0003 & 0.0003 & 0.0003 & 0.0003 & 0.0009 & 0.00075 \\
\hline
\end{tabular}

The methodology presented in Sec. 2.1 was applied to six test cases of HPR turbines operating with air found in the literature. These test cases were selected from the list provided in Table 1 according to the following criteria: 1) they present reliable and well-documented data; 2) they include turbine performance maps at HPR conditions; 3 ) they have similar geometric features, i.e. only nozzled turbines without volute and diffuser. Table 3 lists the employed geometry and input data for the test cases. All test cases used air as working fluid.

The calibration method consists in fitting of the loss models against the mass flow rate and efficiency maps of the selected experimental test cases. Each set of calibration coefficients can be expressed by the array

$$
\overline{\mathrm{X}}=\left\{\mathrm{K}_{\mathrm{p} 1}, \mathrm{~K}_{\mathrm{p} 2}, \mathrm{~K}_{\mathrm{p} 3}, \mathrm{~K}_{\mathrm{inc}}, \mathrm{K}_{\mathrm{vs}}\right\}
$$

where $\mathrm{K}_{\mathrm{p} 1}, \mathrm{~K}_{\mathrm{p} 2}, \mathrm{~K}_{\mathrm{p} 3}, \mathrm{~K}_{\mathrm{inc}}$ and $\mathrm{K}_{\mathrm{vs}}$ are the calibration coefficients in the loss models respectively. The objective of the calibration was to minimise the overall relative root mean square error (RRMSE) in terms of mass flow rate and efficiency. The optimisation function, $\mathrm{f}$, is expressed as 


$$
\begin{aligned}
& \mathrm{f}=\min \left\{\frac{1}{\mathrm{n}_{\mathrm{t}}} \sum_{\mathrm{i}=1}^{\mathrm{n}_{\mathrm{t}}} \operatorname{RRMSE}\left(\eta_{\mathrm{is}, \mathrm{i}}(\overline{\mathrm{X}})\right), \frac{1}{\mathrm{n}_{\mathrm{t}}} \sum_{\mathrm{i}=1}^{\mathrm{n}_{\mathrm{t}}} \operatorname{RRMSE}\left(\dot{\mathrm{m}}_{\mathrm{i}}(\overline{\mathrm{X}})\right)\right\} \\
& \operatorname{RRMSE}\left(\eta_{\mathrm{is}}\right)=\sqrt{\frac{1}{\mathrm{n}_{\mathrm{p}}} \sum_{\mathrm{j}=1}^{\mathrm{n}_{\mathrm{p}}}\left(\frac{\eta_{\text {is,exp }, \mathrm{j}}-\eta_{\mathrm{is}, \mathrm{mod}, \mathrm{j}}(\overline{\mathrm{X}})}{\eta_{\text {is exp }, \mathrm{j}}}\right)^{2}} \\
& \operatorname{RRMSE}(\dot{\mathrm{m}})=\sqrt{\frac{1}{\mathrm{n}_{\mathrm{p}}} \sum_{\mathrm{j}=1}^{\mathrm{n}_{\mathrm{p}}}\left(\frac{\dot{\mathrm{m}}_{\text {exp }, \mathrm{j}}-\dot{\mathrm{m}}_{\text {mod }, \mathrm{j}}(\overline{\mathrm{X}})}{\dot{\mathrm{m}}_{\text {exp }, \mathrm{j}}}\right)^{2}}
\end{aligned}
$$

where $\eta_{\text {is }}$ and $\dot{\mathrm{m}}$ indicate the isentropic efficiency and mass flow rate for $\mathrm{i}=1, \ldots, \mathrm{n}_{\mathrm{t}}$ test cases and $\mathrm{j}=1, \ldots, \mathrm{n}_{\mathrm{p}}$ points in the performance map. The subscripts exp and mod refer to the experimental and mean-line model data, respectively. The multi-objective optimisation was performed by means of a genetic algorithm using 150 generations. When the optimisation is performed, the calibration coefficients are changed in order to provide the best possible agreement with the experimental data. Despite being mathematically consistent, this rationale does not necessarily ensure that the physics of the problem is fully respected. For this reason, two different optimisation cases were considered. In the first case, the optimisation was unconstrained, meaning that there are no specified boundaries on the calibration coefficients and that the optimiser sought the best solution from the mathematical viewpoint. In the second case, the calibration coefficients were constrained by lower and upper bounds, ensuring the correct identification of the choking point. In this case, the optimiser found a solutions which is consistent from both the mathematical and the physical viewpoints. The upper and lower bounds of the calibration coefficients for the constrained optimisation were found by applying the sensitivity analysis approach to identify the boundaries in which the choking point is correctly predicted in all the speed lines of the test case data.

Figure 5: Significance level of the calibration coefficients: (a) on the turbine total-to-static isentropic efficiency; (b) on the mass flow rate. The bars indicate the standard deviation from the mean value. The analysis employed the test cases listed in Table 3.

\subsection{Validation method}

In order to assess the suitability of the loss coefficients obtained after calibration, a validation of the design and off-design models was performed.

The design model was first validated using the test cases which were used for the calibration of the off-design model. Afterwards, its resultes were compared with the mean-line and CFD results at the design point for an ORC turbine operating with the fluid R134a documented in Ref. [76]. This test case was selected for validation due to the presence of sufficient information regarding turbine geometry and flow conditions. The results of Ref. [76] were obtained using two commerciallyavailable software: RITAL (Concepts NREC) for the mean-line design, and Axcent and ANSYS-CFX for the 3D geometry and CFD, respectively. The comparison of results was performed by assigning the same design specifications as in the commercial mean-line software in terms of inlet thermodynamic and flow conditions, turbine geometry and stator outlet Mach number.

The suitability of the off-design model to different geometries and operating conditions was assessed by selecting two specific experimental test cases which were not included among the test cases used for calibration. The first test case is a $2 \mathrm{~kW}$ ORC turbine which was documented and tested by Demierre et al. [31,30]. This test case was selected since it contains the full details of an ORC radial turbine geometry as well as off-design operating data. The turbine operates with the refrigerant R134a in the range of rotational speeds $147000-206000 \mathrm{rpm}$ and pressure ratios 3.1-4.4. This test case is different to those used for calibration in the sense that it has a diffuser. In the validation, the diffuser was modelled using the equations described by Moustapha et al. [59] using a total pressure recovery coefficient of 0.55 . The second test case is the Ricardo C80 turbine documented in Refs. $[1,2]$, which 
was tested up to pressure ratios of 5.0. The geometry differs from those of the calibration test cases by the presence of a volute. In this case, it was assumed that the losses in the volute were small and could be incorporated in the nozzle losses. Moreover, the throat opening was not provided in the original data, and was therefore estimated using a formulation by Li et al. [42]:

$\mathrm{o}_{2}=2 \mathrm{r}_{3} \sin \left(\frac{\theta}{2}\right) \cos \left(\frac{\theta}{2}-\alpha_{3 \mathrm{~b}}-\frac{\gamma}{2}\right)$

Equation 23 assumes a wedge shape for the vane trailing edge with included angle $\gamma=11^{\circ}$ for the Ricardo $\mathrm{C} 80$ turbine and $\theta=2 \pi / \mathrm{Z}_{\mathrm{s}}$ as the center angle in the radial plane.

\section{Results}

\subsection{Sensitivity analysis}

Figure 5 shows the results of the global sensitivity analysis on the efficiency and the mass flow rate. In the sensitivity analysis with respect to the isentropic efficiency, the calibration coefficient $\mathrm{K}_{\mathrm{p} 2}$, associated to the friction losses in the rotor passage, appears to be the most significant parameter with mean values of standardised regression coefficients between approximately 0.76 and 0.98 . The calibration coefficients related to the nozzle passage loss, $\mathrm{K}_{\mathrm{p} 1}$, and the rotor incidence loss, $\mathrm{K}_{\mathrm{inc}}$, appear to be the second most significant ones in some cases. The turbine efficiency results to be less sensitive to the calibration coefficient associated with the rotor secondary flows passage loss, $\mathrm{K}_{\mathrm{p} 3}$.

Finally, the interspace loss calibration coefficients, $\mathrm{K}_{\mathrm{vs}}$, shows very low values of mean and standard deviation, suggesting that its impact on the efficiency is insignificant. The sensitivity analysis of the calibration coefficients with respect to the mass flow rate indicates that, in most cases, $\mathrm{K}_{\mathrm{p} 2}$ has the largest influence on the mass flow rate. In this case, however, $\mathrm{K}_{\mathrm{p} 2}$ presents lower mean values and a larger scatter, which suggests that it has a smaller influence on the mass flow rate compared to the turbine efficiency. It is also noted that $\mathrm{K}_{\mathrm{p} 1}$ has the strongest influence on the mass flow rate in the last test case, suggesting a stronger impact of the nozzle losses in this case. The relatively high standard deviation observed in some test cases (especially for $\mathrm{K}_{\mathrm{p} 1}, \mathrm{~K}_{\mathrm{p} 2}, \mathrm{~K}_{\mathrm{inc}}$ ) indicates that the significance level of the calibration coefficients varies across the operating points of the turbine map and depends on the different flow conditions in the turbine. Moreover, the sensitivity analysis highlights that the significance level of the coefficients depends on the test case. At the same time, the coefficient $\mathrm{K}_{\mathrm{vs}}$ appears to be the least significant from a statistical viewpoint and, henceforth, it was not included as a decision variable in the optimisation. This simplification allows a reduction of the simulation time without compromising significantly the accuracy of the results.

The sensitivity analysis was also applied to identify the range of values for which the calibration coefficients could ensure the identification of the choking point in accordance with the test cases.

\subsection{Calibration}

Figure 6 shows the results of the multi-objective optimisation process with respect to the RRMSE in isentropic efficiency and mass flow rate, namely $\mathrm{RRMSE}_{\eta}$ and $\mathrm{RRMSE}_{\mathrm{m}}$, for the cases of unconstrained and constrained optimisation. The optimal pareto front represented in Figure 6 was found after approximately 120 generations. In the uncostrained optimisation, the optimal solutions range between $2.05 \%$ and $2.17 \%$ in $\mathrm{RRMSE}_{\eta}$, and between $1.45 \%$ and $1.56 \%$ in $\mathrm{RRMSE}_{\mathrm{m}}$. The constrained optimisation used bounds to ensure a suitable identification of the choking point, and reduced the solution space, resulting in higher values of $\mathrm{RRMSE}_{\eta}$, between $2.13 \%$ and $2.8 \%$. Similar values of RRMSE $\mathrm{m}_{\mathrm{m}}$ were found for the constrained and unconstrained optimisations. Each 
point in the pareto front corresponds to a set of optimal calibration coefficients, which can then be selected according to the key-decision criteria set by the designer. In order to select a final set of optimal coefficients in the pareto fronts of Figure 6, an equal weight for the two objective functions was applied. The selected coefficients are listed in Table 4. A comparison of the calibrated coefficients with those of Baines [52] indicate that a $40 \%$ higher nozzle loss coefficient is required to provide a better match with the test cases, as well as lower rotor primary, secondary and incidence loss coefficients.

Table 4: Optimal set of calibration coefficients for an equal weight of $\operatorname{RRMSE}_{\eta}$ and $\mathrm{RRMSE}_{\mathrm{m}}$ in the pareto front.

\begin{tabular}{|c|c|c|}
\hline & unconstrained & constrained \\
\hline $\mathrm{K}_{\mathrm{p} 1}$ & 1.3881 & 1.4152 \\
\hline $\mathrm{K}_{\mathrm{p} 2}$ & 0.637 & 0.5903 \\
\hline $\mathrm{K}_{\mathrm{p} 3}$ & 0.1042 & 0.4036 \\
\hline $\mathrm{K}_{\mathrm{inc}}$ & 0.8952 & 0.8754 \\
\hline
\end{tabular}

Figure 6: Optimal pareto fronts from the unconstrained and constrained multi-objective optimisations. The colours indicate the evolution of the pareto front from the initial $(\circ)$ to the final $(\circ)$ generations.

Figure 7 shows a comparison of the values of $\mathrm{RRMSE}_{\eta}$ and $\mathrm{RRMSE}_{\mathrm{m}}$ for the baseline, unconstrained and constrained optimisation cases. Before calibration of the loss coefficients, the maximum deviation in the single test cases higher, and the overall deviation is approximately $5.88 \%$ in the efficiency and $2.38 \%$ in the mass flow rate. After the optimisation, the overall $\mathrm{RRMSE}_{\eta}$ is reduced to $2.11 \%$ and $2.04 \%$ for the constrained and unconstrained optimisations, respectively. At the same time, the overall $\mathrm{RRMSE}_{\mathrm{m}}$ is decreased to $1.54 \%$ and $1.33 \%$, respectively. Moreover, only a small difference was found between the constrained and unconstrained test cases, as the optimal set of coefficients have also similar values, see Table 4.

Figure 7: Comparison of RRMSE values for the different test cases before and after the optimisation process: (a) RRMSE in isentropic efficiency; (b) RRMSE in mass flow rate.

The Figures 8 and 9 show a visual comparison of the performance maps before and after the calibration process for three exemplary test cases.

Figure 8: Exemplary isentropic efficiency maps before (a,c,e) and after (b,d,f) the multiobjective optimisation: (a,b) Metiner and Glassmann [75] test case; (c,d) McLallin [3] test case; (e,f) Rogo [7] test case.

Figure 9: Exemplary mass flow rate maps before and after the multi-objective optimisation: (a,b) Metiner and Glassmann [75] test case; (c,d) McLallin [3] test case; (e,f) Rogo [7] test case.

Table 5: Comparison of the turbine design model with commercial mean-line and CFD tools presented in Ref. [76].

\begin{tabular}{|l|l|l|l|l|l|l|}
\hline Parameter & Units & RITAL & CFD & present mean-line & deviation (RITAL) & deviation (CFD) \\
\hline $\mathrm{p}_{01} / \mathrm{p}_{06}$ & {$[-]$} & 2.544 & 2.509 & 2.54 & & \\
\hline \multicolumn{2}{|l|}{ Global variables } & & & & $0.0 \%$ & $1.4 \%$ \\
\hline
\end{tabular}




\begin{tabular}{|l|l|l|l|l|l|l|}
\hline \multicolumn{1}{|c|}{$\eta_{t s}$} & {$[-]$} & 76.8 & 83.5 & 81.72 & $4.92 \mathrm{pp}$ & $-1.78 \mathrm{pp}$ \\
\hline \multicolumn{1}{|c|}{$\eta_{t t}$} & {$[-]$} & 79.8 & 87.6 & 86.68 & $6.88 \mathrm{pp}$ & $-0.92 \mathrm{pp}$ \\
\hline $\mathrm{P}$ & {$[\mathrm{kW}]$} & 393.6 & 421.5 & 414.83 & $5.4 \%$ & $-1.6 \%$ \\
\hline \multicolumn{2}{|l|}{ Stator inlet } & & & & & \\
\hline $\mathrm{h}_{01}$ & {$[\mathrm{~kJ} / \mathrm{kg}]$} & 499.2 & 501 & 499.24 & $0.0 \%$ & $-0.4 \%$ \\
\hline $\mathrm{p}_{01}$ & {$[\mathrm{kPa}]$} & 4989.6 & 4849.85 & 5000.00 & $0.2 \%$ & $3.1 \%$ \\
\hline Rotor inlet & & & & & & \\
\hline $\mathrm{M}_{4}$ & {$[-]$} & 0.88 & 0.94 & 0.88 & $0.1 \%$ & $-6.3 \%$ \\
\hline $\mathrm{p}_{04}$ & {$[\mathrm{kPa}]$} & 4886.5 & 4717 & 4822.70 & $-1.3 \%$ & $2.2 \%$ \\
\hline $\mathrm{T}_{04}$ & {$[\mathrm{~K}]$} & 412.2 & 411.9 & 411.71 & $-0.1 \%$ & $0.0 \%$ \\
\hline Rotor outlet & & & & & $-8.6 \%$ \\
\hline $\mathrm{M}_{6}$ & {$[-]$} & 0.363 & 0.364 & 0.33 & $-8.3 \%$ & $1.6 \%$ \\
\hline $\mathrm{p}_{06}$ & {$[\mathrm{kPa}]$} & 1961.4 & 1933.1 & 1964.80 & $0.2 \%$ & $0.6 \%$ \\
\hline $\mathrm{T}_{06}$ & {$[\mathrm{~K}]$} & 370.2 & 367.1 & 369.25 & $-0.3 \%$ & $-0.2 \%$ \\
\hline $\mathrm{h}_{06}$ & {$[\mathrm{~kJ} / \mathrm{kg}]$} & 476.4 & 476.3 & 475.18 & $-0.3 \%$ & \\
\hline
\end{tabular}

$\mathrm{pp}=\%$-points

\subsection{Validation}

Figure 10 depicts the results of the validation of the design model with the experimental test cases.

\begin{tabular}{|l|c|c|c|c|c|c|c|c|c|}
\hline & & & $\mathrm{PR}_{\mathrm{ts}}$ & $\dot{\mathrm{m}}$ & $\mathrm{N}$ & $\mathrm{U} / \mathrm{C}_{0}$ & & $\eta_{\exp }$ & $\begin{array}{c}\text { deviatio } \\
\mathrm{n}\end{array}$ \\
\hline $\begin{array}{l}\text { Test } \\
\text { case }\end{array}$ & $\begin{array}{c}\text { Ref } \\
\cdot\end{array}$ & $\mathrm{No}$ & {$[-]$} & {$[\mathrm{kg} / \mathrm{s}]$} & {$[\mathrm{rpm}]$} & {$[-]$} & {$[-]$} & {$[-]$} & {$[\%]$} \\
\hline $\begin{array}{l}\text { Meitner } \\
\text { and }\end{array}$ & $\begin{array}{c}{[75} \\
]\end{array}$ & 1 & 1.54 & 0.260 & 29550 & 0.700 & $\begin{array}{c}0.89 \\
0(\mathrm{t}- \\
\mathrm{t})\end{array}$ & $\begin{array}{c}0.889 \\
(\mathrm{t}-\mathrm{t})\end{array}$ & $0.10 \%$ \\
\hline $\begin{array}{l}\text { Glassma } \\
\mathrm{n}\end{array}$ & & & & & & & & & \\
\hline $\begin{array}{l}\text { Mc } \\
\text { Lallin }\end{array}$ & {$[3]$} & 2 & 3.23 & 0.187 & 31456 & 0.609 & $\begin{array}{c}0.78 \\
5(\mathrm{t}- \\
\mathrm{s})\end{array}$ & $\begin{array}{c}0.790 \\
(\mathrm{t}-\mathrm{s})\end{array}$ & $-0.49 \%$ \\
\hline Rogo & {$[7]$} & 3 & 4.54 & 1.044 & 16400 & 0.655 & $\begin{array}{c}0.85 \\
0(\mathrm{t}- \\
\mathrm{t})\end{array}$ & $\begin{array}{c}0.878 \\
(\mathrm{t}-\mathrm{t})\end{array}$ & $-2.83 \%$ \\
\hline $\begin{array}{l}\text { Simonyi } \\
\text { rotor 1 }\end{array}$ & {$[9]$} & 4 & 4.99 & 2.361 & 19919 & 0.674 & $\begin{array}{c}0.88 \\
1(\mathrm{t}- \\
\mathrm{t})\end{array}$ & $\begin{array}{c}0.886 \\
(\mathrm{t}-\mathrm{t})\end{array}$ & $-0.48 \%$ \\
\hline
\end{tabular}




\begin{tabular}{|l|c|c|c|c|c|c|c|c|c|}
\hline $\begin{array}{l}\text { Simonyi } \\
\text { rotor 2 }\end{array}$ & {$[9]$} & 5 & 4.99 & 2.350 & 18923 & 0.641 & $\begin{array}{c}0.89 \\
5(\mathrm{t}- \\
\mathrm{t})\end{array}$ & $\begin{array}{c}0.896 \\
(\mathrm{t}-\mathrm{t})\end{array}$ & $-0.10 \%$ \\
\hline $\begin{array}{l}\text { Atkinso } \\
\mathrm{n}\end{array}$ & $\begin{array}{c}{[15} \\
]\end{array}$ & 6 & 3.50 & 0.850 & 39000 & 0.700 & $\begin{array}{c}0.82 \\
3(\mathrm{t}- \\
\mathrm{s})\end{array}$ & $\begin{array}{c}0.840 \\
(\mathrm{t}-\mathrm{s})\end{array}$ & $-1.68 \%$ \\
\hline
\end{tabular}

$(t-t)=$ total-to-total efficiency; $(t-s)=$ total-to-static efficiency

Figure 10: Validation of the turbine design model with experimental data.

The results show that the deviation in efficiency between the model and the experimental data is between $0.1 \%$-points and $2.83 \%$-points. The largest deviation is seen for the test case by Rogo [7]. This deviation can also be seen in Figure 8, which shows that the optimiser found the best data fit by compromising some percentage points in efficiency for the line at $100 \%$ speed. Table 5 reports the comparison between the design results of the present mean-line model and those obtained with two commercial software for the ORC turbine documented in Ref. [76]. The present mean-line model provides power and efficiency predictions closer to the CFD code, with up to $1.6 \%$ and $1.78 \%$-points of deviation, respectively. For the same total-to-total expansion ratio as RITAL, a maximum deviation of $8.3 \%$-points is reported for the rotor exit Mach number conditions. The lower flow velocity at the rotor exit suggests a higher work extraction in the rotor, possibly due to a higher rotor efficiency. This consideration is in agreement with the higher values of power output and isentropic efficiency seen in Table 5 compared to RITAL.

Figures 11(a) and 11(b) show the results of the validation of the off-design model with the test case by Demierre et al. [30, 31]. The mean-line model predicts the mass flow rate within less than $1 \%$ in all operating conditions. The total-to-static efficiency appears to be overpredicted in almost all operating points. The predicted values show a deviation up to $5 \%$ compared to the measured values. However, this deviation is within the uncertainty range of the experimental data.

Figures 11(c) and 11(d) show the results of the validation of the off-design model with the Ricardo turbine $\mathrm{C} 80$. In this test case, the choking point is governed by the nozzle. A good agreement, with a value of RRMSE $_{\mathrm{m}}$ of $1.75 \%$ shown in Figure 11(d), is achieved by estimating the throat opening with Eq. 23. It is worth noting that the use of the simple cosine rule to estimate value of the nozzle throat yields a $20 \%$ lower mass flow rate. This suggests that a more detailed knowledge of the geometry in proximity of the blade throat is essential to predict the correct values of mass flow rate. In terms of efficiency, the results indicate that the model predicts good agreement for low values of rotational speed and velocity ratio $\mathrm{U} / \mathrm{C}_{0}$, while at higher speeds the losses increase, and the maximum point is shifted towards lower values of $\mathrm{U} / \mathrm{C}_{0}$ of about 0.55 .

Figure 11: Validation of the off-design turbine model: (a,b) turbine by Demierre et al. [30, 31]; Ricardo C80 turbine [1, 2]. The error bars represent the uncertainty in the experimental measurements.

\section{Discussion}

In this work, the optimal values of the loss coefficients were identified by the best possible match in the values of mass flow rate, pressure ratio and turbine isentropic efficiency. The model may be employed for the preliminary design and performance prediction of the turbine. However, it was not the objective of this work to assess the suitability of the loss models with respect to the correct prediction of the internal flows in the turbine. In this respect, further conclusions should be drawn only after a detailed comparison with measurements or high-fidelity CFD computations [36]. Detailed CFD studies $[64,66,77]$ on high-pressure ratio turboexpanders indicate that unsteady ReynoldsAveraged Navier Stokes (URANS) simulations can provide a reliable performance estimation. 
Another important aspect concerns the accuracy in the obtained results. The optimal calibration coefficients predicted turbine efficiencies within $\pm 2.1 \%$, and there are limited works in the literature that could be used for comparison. Glassman [55] calibrated the turbine losses using the data of three, low-pressure ratio turbines, showing a deviation within $1 \%$-point. Rodgers [46] validated a RIT model to an accuracy of $\pm 2 \%$ in efficiency. Baines $[52,54,59]$ validated a set of loss correlations using the data of about 30 turbines, showing an overall RRMSE of approximately $5.80 \%$ at the best efficiency points, corresponding to $3.20 \%$-points. This number has the same order of magnitude as that obtained in this work before the optimisation including all the off-design operating points, see Figure 7. These examples indicate that the accuracy obtained by different performance prediction models is in the range from $1 \%$-point to $3.8 \%$-points, suggesting that that the $\pm 2.1 \%$ accuracy in the efficiency of the present model is acceptable.

If additional datasets become available in the literature, other methods such as artificial neural networks may be employed to fit the model. Previous studies [78-80] indicate that neural networks are an effective tool for empirical modelling and optimisation, especially for non-linear systems. However, neural networks require a sufficient amount of training data to ensure a good fit and avoid overfitting [81]. In case the datasets could be extended with a sufficient amount of data, response surface methods could be used to select the datasets for training the neural network [82]. If the available datasets are limited, as in this work, the optimization method presented in this paper is the best option for refitting the calibration coefficients.

The method presented in this paper was calibrated using high-pressure ratio turbines with conventional design features, i.e. radial blade at the rotor inlet, absence of a volute and a diffuser, with rotor tip diameters between 116 and $370 \mathrm{~mm}$, and using air. The same level of accuracy cannot be expected for turbines with different characteristics. The validation with the turbine by Demierre et al. $[30,31]$, which has a tip diameter of $18 \mathrm{~mm}$, uses a refrigerant as the working fluid, and has a diffuser, showed to provide a deviation up to $5 \%$-points in efficiency. The second case of validation was the Ricardo C80 turbine, which differed from the other turbines with a higher ( 80 degrees) nozzle exit angle and by the presence of a volute. It is highlighted that the exact knowledge of the throat geometry is essential to identify the correct values of mass flow rate, and a suitable correlation, as Eq. 23 , should be employed wherever possible.

This work considered only converging nozzle profiles. Reference works in the literature $[36,83]$ indicate that the use of converging blade profiles is preferable up to an exit Mach number of 1.4, resulting in a supersonic post-expansion from the throat to the exit. For higher values of Mach number, strong shock waves and a large supersonic flow deviation occur at the blade exit, producing a dramatic drop in the turbine efficiency. In this case, converging-diverging blade profiles should be considered [36]. The loss correlations presented in this work were developed considering converging profiles blades. For this reason, it is recommended to use them up to the limit Mach number of 1.4 for the reliable application of this steady-state mean-line model.

Finally, it needs to be stressed that the model presented in this paper is subject to the limitations of all steady-state, mean-line models. The model does not attempt to reproduce the full details of the complex three-dimensional flow in the turbine and the corresponding losses. High-fidelity CFD solvers, such as unsteady Reynolds-Averaged Navier Stokes simulations [64, 66, 77], are required to capture the details of the complex flow field within the turbine. In this respect, the integration of mean-line methods and CFD simulations is paramount for the complete fluid-dynamic design of the turbine [36, 84].

\section{Conclusions}

This paper presented for the first time a comprehensive methodology for the preliminary design and performance prediction of radial-inflow turbines for high-pressure ratio applications. A single-stage, radial-inflow turbine model for preliminary design and off-design operation was developed, including consistent modelling strategies for the treatment of choking flow conditions.

A global sensitivity analysis was applied to the model to identify the significance level of the calibration coefficients in the turbine losses with respect to the isentropic efficiency and mass flow 
rate. The turbine loss coefficients were calibrated by minimising the deviation between predicted and measured data for the isentropic turbine efficiency and the mass flow rate across all the off-design data range of six well-documented turbines available in the open literature. The calibration method employed a multi-objective optimisation based on a genetic algorithm, which resulted in a significant reduction in the deviation between the numerical model and the experimental data compared to the baseline case (no calibration). Specifically, the RRMSE across the range of turbine operating conditions decreased from $5.9 \%$ to $2.1 \%$ in the prediction of isentropic efficiency and from $2.4 \%$ to $1.5 \%$ in the prediction of the mass flow rate.

Using the calibrated coefficients, the design model was validated against the turbine data used for calibration, and showed a maximum deviation of $2.83 \%$. The off-design model was validated against the data of an ORC turbine and a turbine using air, both operating at high-pressure ratio conditions. Considering the experimental data uncertainty, the model provided good agreement with the ORC turbine, with less than $1 \%$ deviation in mass flow rate and about $5 \%$ deviation in efficiency. The validation with the air turbine provided good results and it was noted that a careful estimation of the blade throat, based on the detailed characteristics of the nozzle geometry, is paramount to obtain the correct values of the mass flow rate.

The developed turbine design and off-design prediction methodology is applicable to HPR turbines operating with any working fluid in the gas phase. The design and performance prediction models can be expected to provide results within the range of accuracy of the calibrated model for nozzled turbines with geometrical and loading characteristics similar to those used for calibration. A lower accuracy is expected for turbines with different characteristics. In particular, it is important to use or estimate accurate values of throat opening in order to correctly predict the maximum turbine mass flow rate.

\section{Acknowledgements}

The research work was conducted within the frame of the THERMCYC project ("Advanced thermodynamic cycles utilizing low-temperature heat sources"; project ID: 1305-00036B, see http://www . thermcyc. mek.dtu.dk/) funded by Innovation Fund Denmark, The Danish Council for Strategic Research in Sustainable Energy and Environment. The financial support is gratefully acknowledged.

\section{Nomenclature}

\begin{tabular}{|c|c|c|c|c|c|}
\hline Symbols & 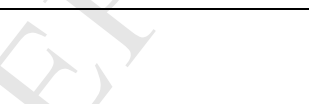 & & $\begin{array}{l}\text { Greek } \\
\text { letters }\end{array}$ & & \\
\hline A & Area & {$\left[\mathrm{m}^{2}\right]$} & $\alpha$ & $\begin{array}{l}\text { Absolute flow } \\
\text { angle }\end{array}$ & {$\left[{ }^{\circ}\right]$} \\
\hline $\mathrm{b}$ & Blade width & {$[\mathrm{m}]$} & $\beta$ & $\begin{array}{l}\text { Relative flow } \\
\text { angle }\end{array}$ & {$\left[{ }^{\circ}\right]$} \\
\hline$\overline{B F}$ & Blockage factor & {$[-]$} & $\rho$ & Density & {$\left[\mathrm{kg} / \mathrm{m}^{3}\right]$} \\
\hline $\mathrm{C}$ & Absolute velocity & {$[\mathrm{m} / \mathrm{s}]$} & $\varepsilon$ & Clearance gap & {$[\mathrm{m}]$} \\
\hline $\mathrm{C}_{0}$ & Spouting velocity & {$[\mathrm{m} / \mathrm{s}]$} & $\eta$ & $\begin{array}{l}\text { Turbine isentropic } \\
\text { efficiency }\end{array}$ & {$[-]$} \\
\hline $\mathrm{c}_{\mathrm{r}}$ & Rotor chord & {$[\mathrm{m}]$} & $\gamma$ & $\begin{array}{l}\text { Nozzle wedge } \\
\text { included angle }\end{array}$ & {$\left[{ }^{\circ}\right]$} \\
\hline $\mathrm{D}_{\mathrm{H}}$ & Hydraulic diameter & {$[\mathrm{m}]$} & $\theta$ & $\begin{array}{l}\text { Nozzle center } \\
\text { angle }\end{array}$ & {$\left[{ }^{\circ}\right]$} \\
\hline$\dot{\mathrm{m}}$ & Mass flow rate & {$[\mathrm{kg} / \mathrm{s}]$} & \multicolumn{2}{|c|}{ Subscripts } & \\
\hline
\end{tabular}




\begin{tabular}{|c|c|c|c|c|}
\hline $\mathrm{h}$ & Specific enthalpy & {$[\mathrm{J} / \mathrm{kg}]$} & 0 & Total \\
\hline$\Delta \mathrm{h}$ & Enthalpy drop & {$[\mathrm{J} / \mathrm{kg}]$} & 1 & Nozzle inlet \\
\hline I & Rothalpy & {$[\mathrm{J} / \mathrm{kg}]$} & 2 & Nozzle throat \\
\hline $\mathrm{k}$ & Specific heat ratio & {$[-]$} & 3 & Nozzle exit \\
\hline $\mathrm{K}_{\mathrm{a}}, \mathrm{K}_{\mathrm{r}}, \mathrm{K}_{\mathrm{ar}}$ & Coefficients in Tab. 2 & {$[-]$} & 4 & Interspace exit \\
\hline $\begin{array}{l}\mathrm{K}_{\mathrm{p} 1}, \mathrm{~K}_{\mathrm{p} 2}, \mathrm{~K}_{\mathrm{p} 3}, \\
\mathrm{~K}_{\mathrm{vs}}, \mathrm{K}_{\mathrm{inc}}\end{array}$ & $\begin{array}{l}\text { Calibration } \\
\text { coefficients }\end{array}$ & {$[-]$} & 5 & Rotor throat \\
\hline$l_{z}$ & Rotor axial length & {$[\mathrm{m}]$} & 6 & Rotor exit \\
\hline $\mathrm{L}_{\mathrm{H}}$ & Hydraulic length & {$[\mathrm{m}]$} & $\mathrm{a}$ & Axial \\
\hline $\mathrm{M}$ & Mach number & {$[-]$} & $\mathrm{b}$ & Blade \\
\hline $\mathrm{N}$ & Rotational speed & [rpm] & $\mathrm{c}$ & Clearance \\
\hline o & Throat opening & {$[\mathrm{m}]$} & ch & Choking \\
\hline $\mathrm{p}$ & Static pressure & {$[\mathrm{Pa}]$} & $\mathrm{h}$ & Hub \\
\hline PR & Pressure ratio & {$[-]$} & inc & Incidence \\
\hline & & & n,noz & Nozzle \\
\hline $\mathrm{r}$ & Radius & {$[\mathrm{m}]$} & pe & Post-expansion \\
\hline $\mathrm{Re}$ & Reynolds number & {$[-]$} & $\mathrm{pl}$ & Passage \\
\hline RRMSE & $\begin{array}{l}\text { Relative Root Mean } \\
\text { Square Error }\end{array}$ & {$[-]$} & opt & Optimal \\
\hline $\mathrm{s}$ & Specific entropy & {$[\mathrm{J} /(\mathrm{kgK})]$} & rel & Relative \\
\hline $\mathrm{t}$ & $\begin{array}{l}\text { Trailing edge } \\
\text { thickness }\end{array}$ & {$[\mathrm{m}]$} & $\mathrm{r}$ & Radial \\
\hline $\mathrm{T}$ & Temperature & {$[\mathrm{K}]$} & rot & Rotor \\
\hline $\mathrm{U}$ & Peripheral velocity & {$[\mathrm{m} / \mathrm{s}]$} & $\mathrm{s}$ & Shroud \\
\hline W & Relative velocity & {$[\mathrm{m} / \mathrm{s}]$} & $\mathrm{t}$ & Trailing edge \\
\hline $\bar{Z}$ & Number of blades & {$[-]$} & ts & Total-to-static \\
\hline \multicolumn{2}{|c|}{ Abbreviation and acronyms } & & $\mathrm{tt}$ & Total-to-total \\
\hline HPR & High-Pressure Ratio & & vs & Interspace \\
\hline ORC & $\begin{array}{l}\text { Organic Rankine } \\
\text { Cycle }\end{array}$ & & & \\
\hline RIT & $\begin{array}{l}\text { Radial-Inflow } \\
\text { Turbines }\end{array}$ & & & \\
\hline
\end{tabular}

\section{References}


[1] G. Hiett, I. Johnston, Experiments Concerning the Aerodynamic Performance of Inward Flow Radial Turbines, in: Proceedings of the Institution of Mechanical Engineers, Conference Proceedings, Vol. 178, SAGE Publications Sage UK: London, England, 1963, pp. 28-42.

[2] X. Qiu, N. Baines, Performance Prediction for High Pressure-Ratio Radial Inflow Turbines, in: ASME Turbo Expo 2007: Power for Land, Sea, and Air, 14-17 May 2007, Montreal, Canada, American Society of Mechanical Engineers, 2007, pp. 945-956.

[3] K. L. McLallin, J. E. Haas, Experimental performance and analysis of 15.04-centimeter-tipdiameter, radial-inflow turbine with work factor of 1.126 and thick blading., Tech. rep., NASA, Washington D.C., USA (1980).

[4] J. Kidwell, G. Large, Advanced technology components for model GTP305-2 aircraft auxiliary power system. Final report 6 May 75-15 Jul 1979, Tech. rep., AiResearch Mfg. Co., Phoenix, AZ, USA (1980).

[5] C. Rogo, T. Hajek, A. Chen, Variable stator radial turbine, Tech. rep., NASA, Washington D.C., USA (1984).

[6] Y. Ribaud, C. Mischel, Study and experiments of a small radial turbine for auxiliary power units, in: ASME 1986 International Gas Turbine Conference and Exhibit, 8-12 June 1986, Dusseldorf, West Germany, American Society of Mechanical Engineers, 1986, pp. V002T04A003-V002T04A003.

[7] C. Rogo, Variable area radial turbine fabrication and test program, Tech. rep., NASA, Washington D.C., USA (1986).

[8] C. Rodgers, Review of mixed flow and radial turbine options, in: 26th Joint Propulsion Conference, 16-18 July 1990, Orlando, FL, USA, 1990, p. 2414.

[9] P. S. Simonyi, R. J. Roelke, R. G. Stabe, B. C. Nowlin, D. Dicicco, Aerodynamic evaluation of two compact radial-inflow turbine rotors, Tech. rep., NASA, Washington D.C., USA (1995).

[10] K. Pullen, N. Baines, S. Hill, The design and evaluation of a high pressure ratio radial turbine, 14 june 1992, cologne, germany, in: ASME 1992 International Gas Turbine and Aeroengine Congress and Exposition, American Society of Mechanical Engineers, 1992, pp. V001T01 A050V001T01A050.

[11] I. Huntsman, H. Hodson, S. Hill, The Design and Testing of a Radial Flow Turbine for Aerodynamic Research, Journal of Turbomachinery 114 (2) (1992) 411-418.

[12] I. Huntsman, H. Hodson, An experimental assessment of the aerodynamic performance of a lowspeed radial inflow turbine, in: 30th Joint Propulsion Conference and Exhibit, 27-29 June 1994, Indianapolis, IN, USA, 1994, pp. 1-8. 
[13] A. C. Jones, Design and Test of a Small, High Pressure Ratio Radial Turbine, Journal of Turbomachinery 118 (2) (1996) 362-370.

[14] S. Spence, D. Artt, Experimental performance evaluation of a $99.0 \mathrm{~mm}$ radial inflow nozzled turbine with different stator throat areas, Proceedings of the Institution of Mechanical Engineers, Part A: Journal of Power and Energy 211 (6) (1997) 477-488.

[15] M. Atkinson, The design of efficient radial turbines for low power applications, Ph.D. thesis, University of Sussex (1998).

[16] W. Doran, S. T. Spence, D. Artt, Experimental performance evaluation of a $99.0 \mathrm{~mm}$ radial inflow nozzled turbine with varying shroud profiles, Proceedings of the Institution of Mechanical Engineers, Part A: Journal of Power and Energy 215 (2) (2001) 267-280.

[17] Z. Feng, Q. Deng, J. Li, Aerothermodynamic Design and Numerical Simulation of Radial Inflow Turbine Impeller for a $100 \mathrm{~kW}$ Microturbine, in: ASME Turbo Expo 2005: Power for Land, Sea, and Air, 6-9 June 2005, Reno, Nevada, USA, American Society of Mechanical Engineers, 2005, pp. 873 880 .

[18] S. Spence, R. Rosborough, D. Artt, G. McCullough, A Direct Performance Comparison of Vaned and Vaneless Stators for Radial Turbines, Journal of turbomachinery 129 (1) (2006) 53-61.

[19] Q. Deng, J. Niu, J. Mao, Z. Feng, Experimental and Numerical Investigation on Overall Performance of a Radial Inflow Turbine for 100kW Microturbine, in: ASME Turbo Expo 2007:

Power for Land, Sea, and Air, 14-17 May 2007, Montreal, Canada, American Society of Mechanical Engineers, 2007, pp. 919-926.

[20] L. Fu, Y. Shi, Q. Deng, H. Li, Z. Feng, Integrated Optimization Design for a Radial Turbine Wheel of a $100 \mathrm{~kW}$-Class Microturbine, Journal of Engineering for Gas Turbines and Power 134 (1) (2011) 012301.

[21] L. Fu, Z.-p. Feng, G.-j. Li, Q.-h. Deng, Y. Shi, T.-y. Gao, Experimental validation of an integrated optimization design of a radial turbine for micro gas turbines, Journal of Zhejiang University SCIENCE A 16 (3) (2015) 241-249.

[22] N. Ino, A. Machida, K. Ttsugawa, Y. Arai, M. Matsuki, H. Hashimoto, A. Yasuda, Development of High Expansion Ratio Helium Turbo Expander, Advances in Cryogenic Engineering 37 (pt B) (1991) 835-844.

[23] S. K. Ghosh, Experimental and computational studies on cryogenic turboexpander, Ph.D. thesis, National Institute of Technology Rourkela (2008).

[24] J. Larjola, ORC power plant based on high speed technology, in: Conference on High Speed Technology, 21-24 August 1988, Lappeenranta, Finland, 1988, pp. 63-77. 
[25] J. Van Buijtenen, J. Larjola, T. Turunen-Saaresti, J. Honkatukia, H. Esa, J. Backman,

A. Reunanen, Design and validation of a new high expansion ratio radial turbine for ORC application, in: Proceedings of the Fifth European Conference on Turbomachinery - Fluid Dynamics and Thermodynamics, 17-22 March 2003, Praha, Czech Republic, 2003, pp. 1-14.

[26] G. Pei, J. Li, Y. Li, D. Wang, J. Ji, Construction and dynamic test of a small-scale organic rankine cycle, Energy 36 (5) (2011) 3215-3223.

[27] S. H. Kang, D. H. Chung, Design and Experimental Study of Organic Rankine Cycle (ORC) and Radial Turbine, in: ASME 2011 Turbo Expo: Turbine Technical Conference and Exposition, 610 June 2011, Vancouver, British Columbia, Canada, International Gas Turbine Institute, 2011, pp. 10371043.

[28] S. H. Kang, Design and experimental study of ORC (organic Rankine cycle) and radial turbine using R245fa working fluid, Energy 41 (1) (2012) 514-524.

[29] S. Han, J. Seo, B.-S. Choi, Development of a $200 \mathrm{~kW}$ ORC radial turbine for waste heat recovery, Journal of Mechanical Science and Technology 28 (12) (2014) 5231-5241.

[30] J. Demierre, D. Favrat, J. Schiffmann, J. Wegele, Experimental investigation of a Thermally Driven Heat Pump based on a double Organic Rankine Cycle and an oil-free Compressor-Turbine Unit, International Journal of Refrigeration 44 (2014) 91-100.

[31] J. Demierre, A. Rubino, J. Schiffmann, Modeling and Experimental Investigation of an Oil-Free Microcompressor-Turbine Unit for an Organic Rankine Cycle Driven Heat Pump, Journal of Engineering for Gas Turbines and Power 137 (3) (2015) 032602.

[32] S. H. Kang, Design and preliminary tests of ORC (organic Rankine cycle) with two-stage radial turbine, Energy 96 (2016) 142-154.

[33] T. Turunen-Saaresti, A. Uusitalo, J. Honkatukia, Design and testing of high temperature microORC test stand using Siloxane as working fluid, Journal of Physics: Conference Series 821 (1) (2017) 012024.

[34] S. L. Dixon, C. A. Hall, Fluid Mechanics and Thermodynamics of Turbomachinery, ButterworthHeinemann, Boston, USA, 2010.

[35] D. Wilson, T. Korakianitis, The Design of High-Efficiency Turbomachinery and Gas Turbines, The MIT Press, Cambridge, Massachusetts, USA, 2014.

[36] G. Persico, M. Pini, Fluid dynamic design of Organic Rankine Cycle turbines, in: Organic Rankine Cycle (ORC) Power Systems: Technologies and Applications, 2016, pp. 253-297. 
[37] A. Verneau, Supersonic turbines for organic fluid Rankine cycles from 3 to $1300 \mathrm{~kW}$, Small High Pressure Ratio Turbines, (VKI Lecture Series 1987-2007) Von Karman Institute For Fluid Dynamics, Rhode-Saint-Genése, Belgium (1987) 1-55.

[38] D. Japikse, Characteristics of a Radial Inflow Turbine With Internal Component Measurements: Part I - Data Review, in: ASME Turbo Expo 2000: Power for Land, Sea, and Air, 8-11 May 2000, Munich, Germany, International Gas Turbine Institute, 2000, pp. V001T03A042-V001T03A042.

[39] R. H. Aungier, Turbine Aerodynamics: Axial-Flow and Radial-Flow Turbine Design and Analysis, ASME Press, New York, USA, 2006.

[40] J. R. Serrano, F. J. Arnau, L. M. García-Cuevas, A. Dombrovsky, H. Tartoussi, Development and validation of a radial turbine efficiency and mass flow model at design and off-design conditions, Energy Conversion and Management 128 (2016) 281-293.

[41] E. Sauret, Open design of high pressure ratio radial-inflow turbine for academic validation, in: ASME 2012 International Mechanical Engineering Congress and Exposition, 9-15 November 2012, Houston, Texas, USA, American Society of Mechanical Engineers, 2012, pp. 3183-3197.

[42] S. Li, E. M. Krivitzky, X. Qiu, Meanline Modeling of a Radial-Inflow Turbine Nozzle With Supersonic Expansion, in: ASME Turbo Expo 2016: Turbomachinery Technical Conference and Exposition, 13-17 June, Seoul, South Korea, International Gas Turbine Institute, 2016, pp. V02DT42A036-V02DT42A036.

[43] L. Kastner, F. Bhinder, A Method for Predicting the Performance of a Centripetal Gas Turbine Fitted With a Nozzle-Less Volute Casing, in: ASME 1975 International Gas Turbine Conference and Products Show, 2-6 March 1975, Houston, Texas, USA, American Society of Mechanical Engineers, 1975, pp. 1-11.

[44] A. J. Glassman, NASA contributions to radial turbine aerodynamic analyses, in: Automotive Technol. Develop. Contractor Coord. Meeting; 11-13 Nov. 1980, Dearborn, MI, United States, 1980, pp. 1-20.

[45] A. Perdichizzi, G. Lozza, Design Criteria and Efficiency Prediction for Radial Inflow Turbines, in: Gas Turbine Conference and Exhibition, Anaheim, California, May 31-June 4, 1987, pp. 1-9.

[46] C. Rodgers, Mainline performance prediction for radial inflow turbines, Tech. rep., Von Karman Inst. for Fluid Dynamics, Lecture Series on Small High Pressure Ratio Turbines (1987).

[47] S. K. Ghosh, R. K. Sahoo, S. K. Sarangi, Mathematical Analysis for Off-Design Performance of Cryogenic Turboexpander, Journal of Fluids Engineering 133 (3) (2011) 031001. 
[48] C. A.M. Ventura, P. A. Jacobs, A. S. Rowlands, P. Petrie-Repar, E. Sauret, Preliminary Design and Performance Estimation of Radial Inflow Turbines: An Automated Approach, Journal of Fluids Engineering 134 (3) (2012) 031102.

[49] K. Rahbar, S. Mahmoud, R. K. Al-Dadah, N. Moazami, Parametric analysis and optimization of a small-scale radial turbine for Organic Rankine Cycle, Energy 83 (2015) 696-711.

[50] L. Da Lio, G. Manente, A. Lazzaretto, A mean-line model to predict the design efficiency of radial inflow turbines in organic Rankine cycle (ORC) systems, Applied Energy 205 (2017) 187-209.

[51] V. Mounier, L. E. Olmedo, J. Schiffmann, Small scale radial inflow turbine performance and predesign maps for Organic Rankine Cycles, Energy 143 (2018) 1072-1084.

[52] N. Baines, A meanline prediction method for radial turbine efficiency, in: Sixth International Conference on Turbocharging and air management systems, 3-5 November 1998, London, UK, Professional Engineering Publishing, 1998, pp. 45-56.

[53] N. Baines, Radial- and mixed-flow turbine options for high-boost turbochargers, in: Seventh International Conference on Turbochargers and Turbocharging, 14-15 May 2002, London, UK, Professional Engineering Publishing Limited, 2002, pp. 35-44.

[54] N. Baines, Radial turbines: An integrated design approach, in: 6th Conference on Turbomachinery: Fluid Dynamics and Thermodynamics, 7-11 November 2005, Lille, France, 2005, pp. $1-10$.

[55] A. J. Glassman, Enhanced analysis and users manual for radial-inflow turbine conceptual design code RTD, Tech. rep., NASA, Washington D.C., USA (1995).

[56] S. Bahamonde, M. Pini, C. De Servi, A. Rubino, P. Colonna, Method for the Preliminary Fluid Dynamic Design of High-Temperature Mini-Organic Rankine Cycle Turbines, Journal of Engineering for Gas Turbines and Power 139 (8) (2017) 082606.

[57] The Mathworks Inc., MATLAB - MathWorks (2016).

URL http: //Www. mathworks . com/products/matlab/

[58] I. H. Bell, J. Wronski, S. Quoilin, V. Lemort, Pure and pseudo-pure fluid thermophysical property evaluation and the open-source thermophysical property library CoolProp, Industrial \& Engineering Chemistry Research 53 (6) (2014) 2498-2508.

[59] H. Moustapha, M. F. Zelesky, N. C. Baines, D. Japikse, Axial and Radial Turbines, Concepts NREC, White River Junction, VT, USA, 2003.

[60] A. Meroni, A. La Seta, J. G. Andreasen, L. Pierobon, G. Persico, F. Haglind, Combined Turbine and Cycle Optimization for Organic Rankine Cycle Power Systems - Part A: Turbine Model, Energies 9 (5) (2016) 313. 
[61] M. C. Robertson, A. W. Costall, P. J. Newton, R. F. Martinez-Botas, Radial Turboexpander Optimization Over Discretized Heavy-Duty Test Cycles for Mobile Organic Rankine Cycle Applications, in: Proceedings of ASME Turbo Expo 2016: Turbomachinery Technical Conference and Exposition, 13-17 June 2016, Seoul, South Korea, International Gas Turbine Institute, 2016, pp. $1-14$.

[62] J. D. Stanitz, One-dimensional compressible flow in vaneless diffusers of radial-and mixed-flow centrifugal compressors, including effects of friction, heat transfer and area change, Tech. rep., NASA, Washington D.C., USA (1952).

[63] A. Whitfield, N. C. Baines, Design of Radial Turbomachines, John Wiley and Sons Inc., New York, NY, USA, 1990.

[64] F. Rubechini, M. Marconcini, A. Arnone, A. S. Del Greco, R. Biagi, Special Challenges in the Computational Fluid Dynamics Modeling of Transonic Turbo-Expanders, Journal of Engineering for Gas Turbines and Power 135 (10) (2013) 102701.

[65] J. Harinck, D. Pasquale, R. Pecnik, J. van Buijtenen, P. Colonna, Performance improvement of a radial organic Rankine cycle turbine by means of automated computational fluid dynamic design, Proceedings of the Institution of Mechanical Engineers, Part A: Journal of Power and Energy 227 (6) (2013) 637-645.

[66] E. Rinaldi, R. Pecnik, P. Colonna, Unsteady Operation of a Highly Supersonic Organic Rankine Cycle Turbine, Journal of Turbomachinery 138 (12) (2016) 121010.

[67] H. E. Rohlik, M. G. Kofskey, Recent radial turbine research at the NASA Lewis Research Center, in: ASME 1972 International Gas Turbine and Fluids Engineering Conference and Products Show, 26-30 March 1972, San Francisco, California, USA, American Society of Mechanical Engineers, 1972, pp. V001T01A041-V001T01A041.

[68] D. Artt, S. Spence, A loss analysis based on experimental data for a $99.0 \mathrm{~mm}$ radial inflow nozzled turbine with different stator throat areas, Proceedings of the Institution of Mechanical Engineers, Part A: Journal of Power and Energy 212 (1) (1998) 27-42.

[69] S. K. Ghosh, R. Sahoo, S. K. Sarangi, Mathematical Analysis for Off-Design Performance of Cryogenic Turboexpander, Journal of Fluids Engineering 133 (3) (2011) 031001.

[70] H.-C. Jung, S. Krumdieck, Meanline design of a $250 \mathrm{~kW}$ radial inflow turbine stage using R245fa working fluid and waste heat from a refinery process, Proceedings of the Institution of Mechanical Engineers, Part A: Journal of Power and Energy 230 (4) (2016) 402-414. 
[71] D. Japikse, Advanced diffusion levels in turbocharger compressors and component matching, in: 1st International Conference on Turbocharging and Turbochargers, 26-28 April 1982, London, UK, 1982, pp. 143-155.

[72] J. W. Daily, R. E. Nece, Chamber Dimension Effects on Induced Flow and Frictional Resistance of Enclosed Rotating Disks, Journal of Basic Engineering 82 (1) (1960) 217-230.

[73] N. Metropolis, S. Ulam, The Monte Carlo Method, Journal of the American Statistical Association 44 (247) (1949) 335-341.

[74] A. Meroni, J. Andreasen, G. Persico, F. Haglind, Optimization of organic Rankine cycle power systems considering multistage axial turbine design, Applied Energy 209 (2018) 339-354.

[75] P. Meitner, A. Glassman, Computer Program for Off-Design Performance Analysis of Radial Inflow Turbines with Rotor Blade Sweep, Tech. rep., NASA, Washington D.C., USA (1983).

[76] E. Sauret, Y. Gu, Three-dimensional off-design numerical analysis of an organic Rankine cycle radial-inflow turbine, Applied Energy 135 (2014) 202-211.

[77] M. Marconcini, F. Rubechini, A. Arnone, A. S. Del Greco, R. Biagi, Aerodynamic Investigation of a High Pressure Ratio Turbo-Expander for Organic Rankine Cycle Applications, in: Proceedings of ASME Turbo Expo 2012, June 11-15, Copenhagen, Denmark, 2012, pp. 1-10.

[78] I. Yusri, A. Abdul Majeed, R. Mamat, M. Ghazali, O. I. Awad, W. Azmi, A review on the application of response surface method and artificial neural network in engine performance and exhaust emissions characteristics in alternative fuel, Renewable and Sustainable Energy Reviews 90 (2018) 665-686.

[79] D. Ba, I. H. Boyaci, Modeling and optimization II: Comparison of estimation capabilities of response surface methodology with artificial neural networks in a biochemical reaction, Journal of Food Engineering 78 (3) (2007) 846-854.

[80] K. Nasouri, A. M. Shoushtari, M. Khamforoush, Comparison between artificial neural network and response surface methodology in the prediction of the production rate of polyacrylonitrile electrospun nanofibers, Fibers and Polymers 14 (11) (2013) 1849-1856.

[81] A. Pacheco-Vega, M. Sen, K. T. Yang, R. L. McClain, Neural network analysis of fin-tube refrigerating heat exchanger with limited experimental data, International Journal of Heat and Mass Transfer 44 (4) (2001) 763-770.

[82] J. Cheng, Q. S. Li, R.-C. Xiao, A new artificial neural network-based response surface method for structural reliability analysis, Probabilistic Engineering Mechanics 23 (2008) 51-63.

[83] C. Osnaghi, Teoria delle turbomacchine, Società Editrice Esculapio, 2013. 
[84] D. Fiaschi, G. Innocenti, G. Manfrida, F. Maraschiello, Design of micro radial turboexpanders for ORC power cycles: From 0D to 3D, Applied Thermal Engineering 99 (2016) 402-410. doi:10.1016/j . applthermaleng . 2015 .11 . 087. 


\section{Highlights}

- A mean-line model for high-pressure ratio radial-inflow turbines is presented.

- Modelling strategies for the treatment of choking conditions are detailed.

- The loss models arecalibrated with the experimental data of six turbines.

- The calibration allowed reducing the deviation with the experimental data.

- The mean-line model is validated with other two test cases within $5 \%$ accuracy. 